\title{
Sterically Controlled Late-Stage C-H Alkynylation of Arenes
}

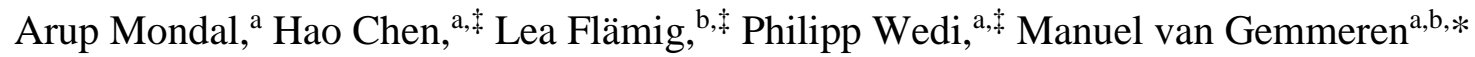 \\ [a] Max-Planck-Institute for Chemical Energy Conversion, Stiftstraße 34-36, 45470 Mülheim an der Ruhr, Germany. [b] \\ Westfälische Wilhelms-Universität Münster, Corrensstraße 40, 48149 Münster, Germany.
}

Alkynylation, C-H Activation, Dual-Ligand Catalysis, Palladium Catalysis, Late-Stage Modification

\begin{abstract}
Phenylacetylenes are key structural motifs in organic chemistry, which find widespread applications in bioactive molecules, synthetic intermediates, functional materials and reagents. These molecules are typically prepared from prefunctionalized starting materials, e.g. using the Sonogashira coupling, or using directing group-based $\mathrm{C}-\mathrm{H}$ activation strategies. While highly efficient, these approaches remain limited by their inherent selectivities for specific regioisomers. Herein we present a complementary approach based on an arene-limited nondirected $\mathrm{C}-\mathrm{H}$ activation. The reaction is predominantly controlled by steric rather than electronic factors and thereby gives access to a complementary product spectrum with respect to traditional methods. A broad scope as well as the suitability of this protocol for late-stage functionalization are demonstrated.
\end{abstract}

The alkyne motif constitutes one of the most fundamental functional groups in organic chemistry. ${ }^{1}$ It is therefore not surprising that aryl-substituted alkynes, or phenylacetylenes, feature in a wide range of contexts, as bioactive molecules, ${ }^{2}$ synthetic intermediates, ${ }^{3}$ functional materials, ${ }^{4}$ reagents (e.g. for click chemistry), ${ }^{5}$ etc. In light of the importance of these compounds a convenient access to all regioisomers of phenylacetylenes is highly desirable, especially when considering the importance of compound libraries in medicinal chemistry, where the flexible introduction of substituents into advanced synthetic intermediates is essential.

The arguably most prominent reaction for the synthesis of phenylacetylene-derivatives is the Sonogashira coupling, ${ }^{6}$ which requires the presence of a (pseudo)halide in the arene substrate. The regioselectivity of this approach is thus dictated by the regioselectivity of a preceding (pseudo)halogenation step (Scheme 1, path a). Accordingly, ortho and para products are expected to dominate for substrates bearing donor substituents, while meta products are expected for substrates bearing acceptors. ${ }^{7}$ Alternatively, when substrates bear a suitable directing group, in many cases specifically introduced for this purpose, a directed $\mathrm{C}$ $\mathrm{H}$ alkynylation can be performed, which proceeds with orthoselectivity (path b). ${ }^{8,9}$

While there are ample methods for the synthesis of ortho and para alkynylated arenes respectively, a method generally favoring the meta isomer regardless of the donor/acceptor-properties of the substituents on the substrate is currently not available.

Inspired by the ground breaking studies by the groups of Maleczka, Smith, and coworkers ${ }^{10}$ as well as Ishiyama, Hartwig,
Miyaura and coworkers ${ }^{11}$ on the Ir-catalyzed borylation of arenes, as well as later studies on related silylations, ${ }^{12}$ we hypothesized that such a method could be enabled through a nondirected catalyst system predominantly sensitive to steric rather than electronic control (path c).$^{13}$ At the same time the well-documented suitability of Pd-catalysts to induce aryl-alkyne bond formation encouraged us to choose this metal for catalyst design. ${ }^{6}$ We realized that, in order to enable the desired process, a Pd-catalyst would be required that is capable of activating arene $\mathrm{C}-\mathrm{H}$ bonds in arenes without the need for a directing group.

Scheme 1. Approaches towards the regioselective $\mathrm{C}-\mathrm{H}$ alkynylation of arenes.

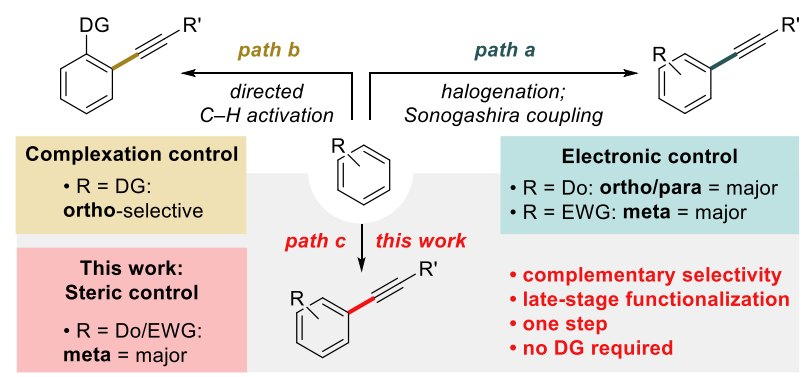

Traditionally, such processes could only be induced through the use of a large excess of the arene substrate, a limitation that was recently overcome through careful catalyst design by ourselves and others. ${ }^{14}$ Encouraged by the observation that our method based on dual ligand catalysis was sensitive to both steric and electronic control, we argued that it might be possible to further elaborate this strategy in order to enable a sterically controlled late-stage alkynylation of arenes.

In a continuation of our interest in the development of methods for the synthesis of challenging phenylacetylene derivatives, ${ }^{15}$ we herein report our realization of this goal.

Starting from the reaction conditions utilized in our previous olefination and cyanation methods and using 1-Bromo-2(triisopropylsilyl)acetylene as reagent, ${ }^{14 c, 14 \mathrm{~d}}$ we conducted an extensive screening of catalysts and reaction conditions. We aimed not only to maximize the overall yield of the process, which besides maximizing the $\mathrm{C}-\mathrm{H}$ activation efficiency involved the additional challenge of suppressing undesired reagent dimerization, ${ }^{16}$ but also the sensitivity of the catalyst system to steric influences (see the Supporting Information for details). These studies allowed us to identify the reaction conditions shown in Scheme 2. 
Scheme 2: Reaction scope. ${ }^{a}$
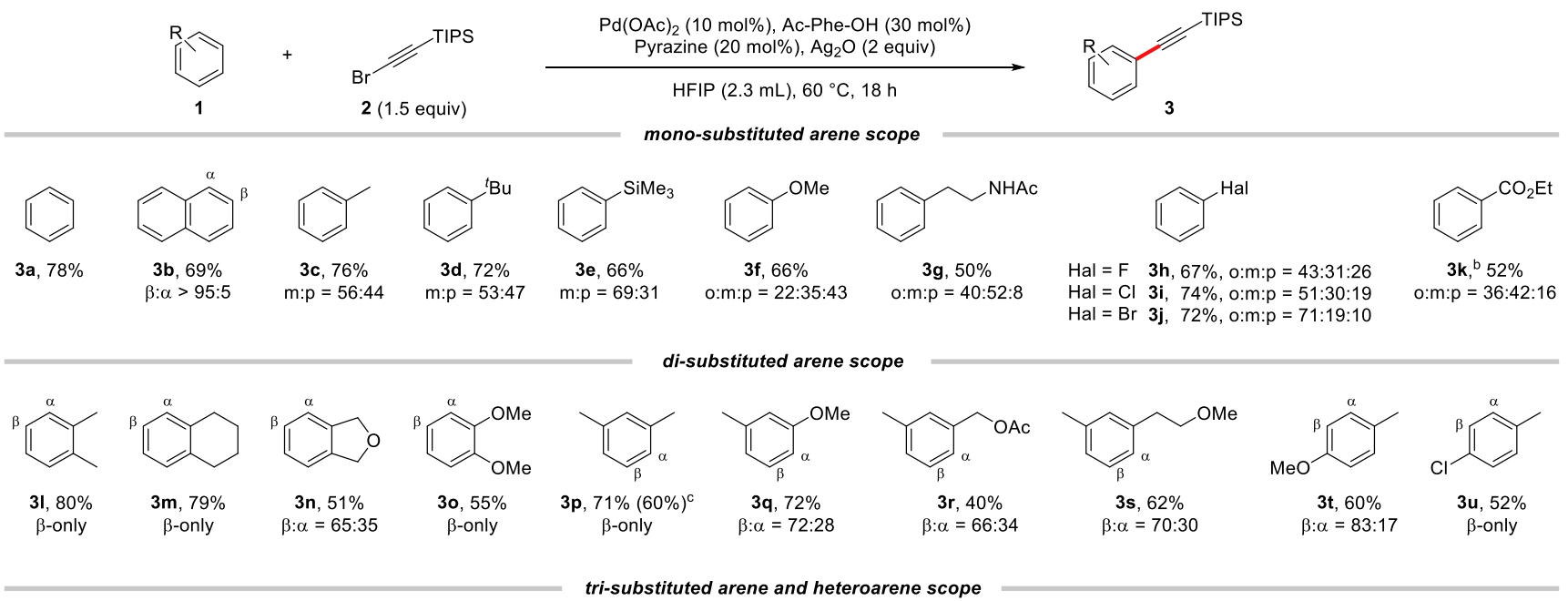

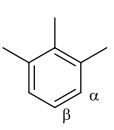

$3 v, 69 \%$

$\beta$-only

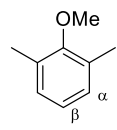

$3 \mathbf{w}, 75 \%$
$\beta$-only

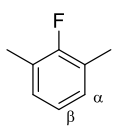

$3 \mathbf{x}, 60 \%$

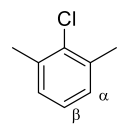

$3 y, 67 \%$
$\beta$-only<smiles>COc1cc(C)ccc1Cl</smiles>

$3 \mathrm{z}, 55 \%$

$\beta$-only

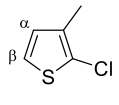

3aa, ${ }^{d} 78 \%$

$\beta: \alpha=91: 9$

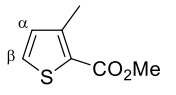

$3 a b,{ }^{d} 61 \%$

$\beta$-only

${ }^{\mathrm{a}}$ All reactions were conducted on a $0.2 \mathrm{mmol}$ scale. ${ }^{\mathrm{b}} \mathrm{This}$ reaction was conducted at $70{ }^{\circ} \mathrm{C}$. ${ }^{\mathrm{c}}$ The yield given in parenthesis was obtained on a $5 \mathrm{mmol}$ scale. ${ }^{\mathrm{d}}$ This reaction was performed in $\operatorname{HFIP/DMSO}(1: 1,2.3 \mathrm{~mL})$.

Under these conditions simple benzene (3a) and naphthalene (3b) underwent smooth alkynylation. A wide range of monosubstituted arenes could be functionalized to give $\mathbf{3 c}-\mathbf{k}$, with electronic properties ranging from electron-rich anisole (3f) to electron-poor ethyl benzoate (3k). Our studies on these simple arenes revealed that the reaction is highly sensitive to steric effects, with even a methyl-group being sufficient to completely suppress the formation of ortho product. Electronic effects were found to be less dominant, evidenced for example by the formation of substantial amounts of meta product from anisole (3f). Finally, we observed an unusually strong directing effect exerted by halide substituents, which led to the formation of ortho-products as the major components (3h-j). These observations imply, that in more complex substrates, high regioselectivities can be expected in many cases. Accordingly, when we studied 1,2-di-substituted arenes, single isomers were obtained in most cases (3l-o). We thus proceeded to study 1,3-di-substituted substrates. In these substrates, the electronically and sterically preferred positions are in competition with one another and we observed the formation of the sterically favored position as the major or only product in all cases (3p-s). It is particularly remarkable that even the strong directing effect exerted by a methoxy-group can be overcome in favor of the sterically more accessible position (3q). Good regioselectivities were also observed for 1,4-di-substituted substrates (3t-u). Similarly, 1,2,3-tri-substituted arenes delivered single products in all cases studied (3v-y) and a 1,2,4-tri-substituted substrate could be functionalized with perfect regiocontrol (3z). Finally, our protocol was also found to be amenable to thiophene derivatives (3aa-ab).

The unusually strong sensitivity of our catalyst to steric rather than electronic control of the site-selectivity, together with the ability to employ the arene as the limiting reagent implies that this method may be highly useful to access otherwise challenging products in late-stage modifications.

In order to probe this potential, we tested our protocol with a series of structurally complex small molecules as substrates (Scheme 3).
Scheme 3. Suitability for late-stage modification. ${ }^{a}$
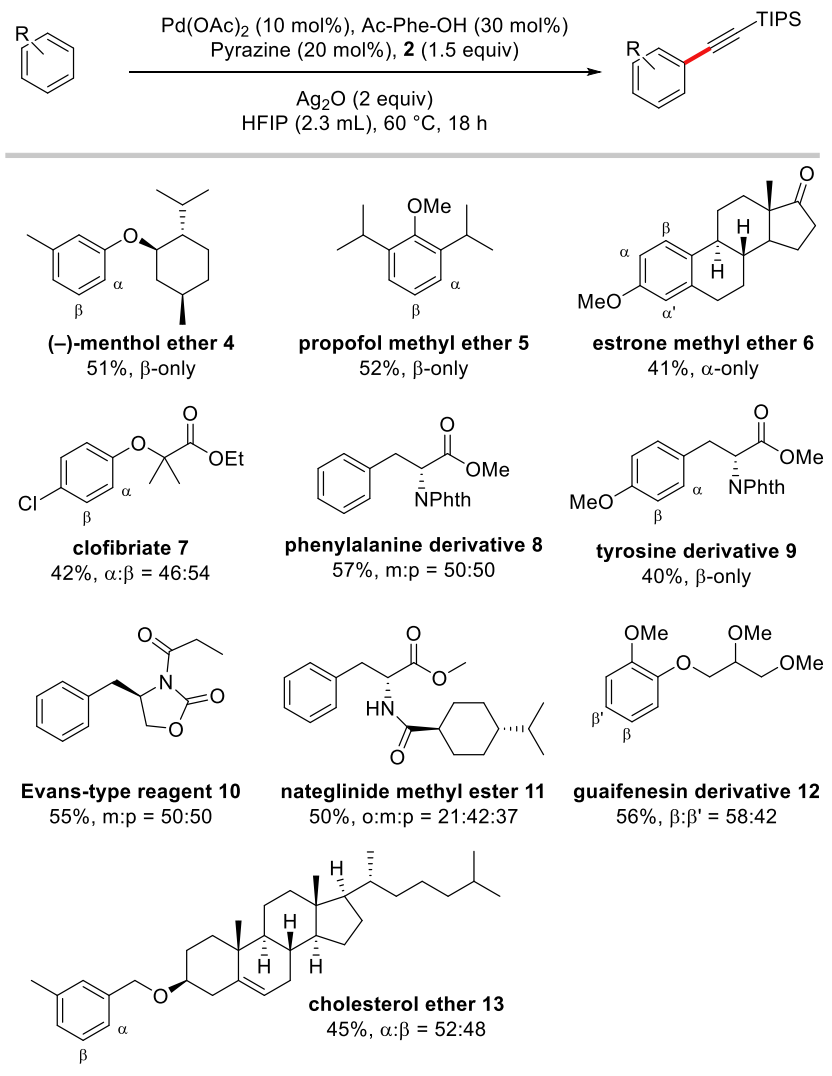

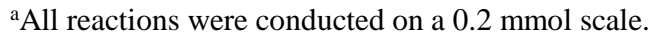

The (-)-menthol ether of $m$-cresol could be alkynylated with perfect regiocontrol in favor of the sterically-favored but electronically disfavored $\beta$-position (4). Similarly, the products derived from propofol methyl ether and estrone methyl ether $(\mathbf{5}$ and 
6) were obtained as single regioisomers. The lipid-lowering agent clofibrate (7), protected phenylalanine (8) and tyrosine (9), an Evans-type reagent (10), as well as derivatives of nateglinide (11), guaifenesin (12), and cholesterol (13) could all be alkynylated, giving access to regioisomers, which would otherwise be challenging to obtain. These studies also revealed that a wide range of functional groups is tolerated in this protocol, such as ethers (4$\mathbf{7}, \mathbf{1 2}, \mathbf{1 3})$, ketones $(\mathbf{6})$, halides $(\mathbf{7})$, esters $(\mathbf{7 - 9}, \mathbf{1 1})$, imides $(\mathbf{8}, \mathbf{9})$, and amides $(\mathbf{1 0}, \mathbf{1 1})$.

Finally, we engaged in a case study on the complementarity between our protocol and traditional approaches (Scheme 4). To this end, the silyl-protected meta-cresol 14 was first subjected to a sequence of bromination, Sonogashira coupling, and deprotection (path a). The regioselectivity of this sequence is determined in the bromination step, which proceeds under electronic control, thereby resulting in the formation of product $\mathbf{1 5}$, in which alkynylation has been achieved selectively in the $\gamma$-position. The synthesis of the corresponding $\alpha$-isomer 16 starting from meta-cresol has been described using several directing groups (path b). ${ }^{17}$

Scheme 4. Complementarity with traditional approaches.

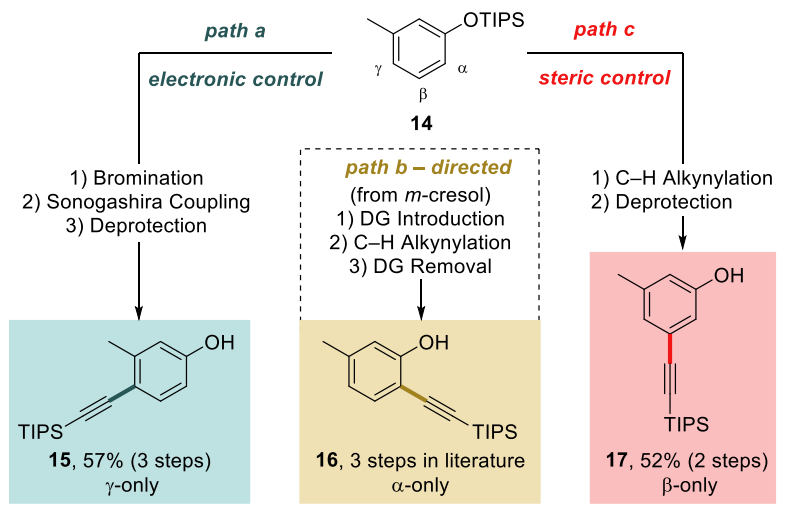

Our protocol perfectly complements these two synthetic sequences. Starting from substrate 14; the sterically controlled alkynylation, followed by deprotection, delivered the $\beta$-isomer $\mathbf{1 7}$ selectively (path c).

In summary, we have developed the first Pd-catalyzed nondirected $\mathrm{C}-\mathrm{H}$ alkynylation of arenes. The reaction was found to possess a wide substrate scope, tolerating a broad range of functional groups. A key feature of this protocol is the strong influence of steric control on the site-selectivity, which renders the reaction complementary to established synthetic strategies. We have demonstrated the suitability of this protocol, which employs the arene as the limiting reagent, for late-stage functionalization and expect that its ability to give access to otherwise challenging regioisomers will prove highly valuable in this context.

\section{ASSOCIATED CONTENT}

\section{Supporting Information}

The Supporting Information is available free of charge on the ACS Publications website.

Preparative procedures and analytical data.

\section{AUTHOR INFORMATION}

\section{Corresponding Author}

*mvangemmeren@uni-muenster.de.

\section{Author Contributions}

$\$$ H.C., L.F., and P.W. contributed equally to this work.
Notes

The authors declare no competing financial interests.

\section{ACKNOWLEDGMENT}

We gratefully acknowledge financial support from the Max Planck Society (Otto Hahn Award to M.v.G.), FCI (Liebig Fellowship to M.v.G.), and WWU Münster. We thank the members of our NMR and MS departments for their excellent service, as well as S. Bognar, M. Farizyan, and Dr. T. Patra for valuable discussions. Furthermore, we are indebted to Prof. F. Glorius for his generous support.

\section{REFERENCES}

(1) (a) Modern Acetylene Chemistry; Wiley-VCH Verlag GmbH: Weinheim, 1995; (b) Acetylene Chemistry: Chemistry, Biology, and Material Science; Wiley-VCH Verlag GmbH \& Co. KGaA: Weinheim, 2005.

(2) (a) Duvic, M. Tazarotene: a review of its pharmacological profile and potential for clinical use in psoriasis, Expert Opinion on Investigational Drugs 1997, 6, 1537; (b) Tang, P. A.; Tsao, M.-S.; Moore, M. J. A review of erlotinib and its clinical use, Expert Opinion on Pharmacotherapy 2006, 7, 177; (c) Talpur, R.; Cox, K.; Duvic, M. Efficacy and safety of topical tazarotene: a review, Expert Opinion on Drug Metabolism \& Toxicology 2009, 5, 195; (d) Yang, Z.-Y.; Yuan, J.-Q.; Di, M.-Y.; Zheng, D.-Y.; Chen, J.-Z.; Ding, H.; Wu, X.Y.; Huang, Y.-F.; Mao, C.; Tang, J.-L. Gemcitabine Plus Erlotinib for Advanced Pancreatic Cancer: A Systematic Review with MetaAnalysis, PLOS ONE 2013, 8, e57528; (e) Hoy, S. M. Ponatinib: A Review of Its Use in Adults with Chronic Myeloid Leukaemia or Philadelphia Chromosome-Positive Acute Lymphoblastic Leukaemia, Drugs 2014, 74, 793.

(3) (a) Hintermann, L.; Labonne, A. Catalytic Hydration of Alkynes and Its Application in Synthesis, Synthesis 2007, 2007, 1121; (b) Severin, R.; Doye, S. The catalytic hydroamination of alkynes, Chem. Soc. Rev. 2007, 36, 1407; (c) Chinchilla, R.; Nájera, C. Chemicals from Alkynes with Palladium Catalysts, Chem. Rev. 2014, 114, 1783; (d) Fürstner, A. In Handbook of Metathesis; WileyVCH Verlag GmbH \& Co. KGaA: 2015, p 445; (e) Li, J.; Lee, D. In Handbook of Metathesis; Wiley-VCH Verlag GmbH \& Co. KGaA: 2015, p 381.

(4) (a) Diederich, F.; Rubin, Y. Synthetic Approaches toward Molecular and Polymeric Carbon Allotropes, Angew. Chem. Int. Ed. Engl. 1992, 31, 1101; (b) H. F. Bunz, U.; Rubin, Y.; Tobe, Y. Polyethynylated cyclic $\pi$-systems: scaffoldings for novel two and three-dimensional carbon networks, Chem. Soc. Rev. 1999, 28, 107. (5) (a) Lutz, J.-F. 1,3-Dipolar Cycloadditions of Azides and Alkynes: A Universal Ligation Tool in Polymer and Materials Science, Angew. Chem. Int. Ed. 2007, 46, 1018; (b) Meldal, M.; Tornøe, C. W. Cu-Catalyzed Azide-Alkyne Cycloaddition, Chem. Rev. 2008, 108, 2952; (c) Brand, J. P.; Waser, J. Electrophilic alkynylation: the dark side of acetylene chemistry, Chem. Soc. Rev. 2012, 41, 4165.

(6) (a) Sonogashira, K. In Handbook of Organopalladium Chemistry for Organic Synthesis; John Wiley \& Sons, Inc.: 2003, p 493; (b) Chinchilla, R.; Nájera, C. The Sonogashira Reaction: A Booming Methodology in Synthetic Organic Chemistry, Chem. Rev. 2007, 107, 874; (c) Chinchilla, R.; Nájera, C. Recent advances in Sonogashira reactions, Chem. Soc. Rev. 2011, 40, 5084.

(7) It should be noted that for some very electron-poor or electron-rich arenes, a para-selective $\mathrm{C}-\mathrm{H}$ alkynylation has also been reported: (a) de Haro, T.; Nevado, C. Gold-Catalyzed Ethynylation of Arenes, J. Am. Chem. Soc. 2010, 132, 1512; (b) Wei, Y.; Zhao, H.; Kan, J.; Su, W.; Hong, M. Copper-Catalyzed Direct Alkynylation of Electron-Deficient Polyfluoroarenes with Terminal Alkynes Using $\mathrm{O} 2$ as an Oxidant, J. Am. Chem. Soc. 2010, 132, 2522; (c) Brand, J. P.; Waser, J. Para-Selective Gold-Catalyzed Direct Alkynylation of Anilines, Org. Lett. 2012, 14, 744; (d) Brand, J. P.; Li, Y.; Waser, J. Gold-Catalyzed Alkynylation: Acetylene-Transfer instead of Functionalization, Irsael J. Chem. 2013, 53, 901.

(8) (a) Kobayashi, K.; Arisawa, M.; Yamaguchi, M. $\mathrm{GaCl}_{3-}$ Catalyzed Ortho-Ethynylation of Phenols, J. Am. Chem. Soc. 2002, 124, 8528; (b) Amemiya, R.; Fujii, A.; Yamaguchi, M. GaCl3- 
Catalyzed ortho-ethynylation reaction of $\mathrm{N}$-benzylanilines, Tetrahedron Lett. 2004, 45, 4333; (c) Tobisu, M.; Ano, Y.; Chatani, $\mathrm{N}$. Palladium-Catalyzed Direct Alkynylation of $\mathrm{C}-\mathrm{H}$ Bonds in Benzenes, Org. Lett. 2009, 11, 3250; (d) Ano, Y.; Tobisu, M.; Chatani, N. Palladium-Catalyzed Direct ortho-Alkynylation of Aromatic Carboxylic Acid Derivatives, Org. Lett. 2012, 14, 354; (e) Kim, S. H.; Park, S. H.; Chang, S. Palladium-catalyzed oxidative alkynylation of arene $\mathrm{C}-\mathrm{H}$ bond using the chelation-assisted strategy, Tetrahedron 2012, 68, 5162; (f) Zhao, Y.; He, G.; Nack, W. A.; Chen, G. Palladium-Catalyzed Alkenylation and Alkynylation of ortho-C $\left(\mathrm{sp}^{2}\right)-\mathrm{H}$ Bonds of Benzylamine Picolinamides, Org. Lett. 2012, 14, 2948; (g) Feng, C.; Loh, T.-P. Rhodium-Catalyzed C-H Alkynylation of Arenes at Room Temperature, Angew. Chem. Int. Ed. 2014, 53, 2722; (h) Shang, M.; Wang, H.-L.; Sun, S.-Z.; Dai, H.-X.; Yu, J.-Q. Cu(II)-Mediated Ortho C-H Alkynylation of (Hetero)Arenes with Terminal Alkynes, J. Am. Chem. Soc. 2014, 136, 11590; (i) Theunissen, C.; Evano, G. Room-Temperature Direct Alkynylation of Arenes with Copper Acetylides, Org. Lett. 2014, 16, 4488; (j) Xie, F.; Qi, Z.; Yu, S.; Li, X. Rh(III)- and Ir(III)-Catalyzed C-H Alkynylation of Arenes under Chelation Assistance, J. Am. Chem. Soc. 2014, 136, 4780; (k) Liu, Y.-H.; Liu, Y.-J.; Yan, S.-Y.; Shi, B.-F. Ni(ii)-catalyzed dehydrative alkynylation of unactivated (hetero)aryl $\mathrm{C}-\mathrm{H}$ bonds using oxygen: a user-friendly approach, Chem. Commun. 2015, 51 , 11650; (I) Yi, J.; Yang, L.; Xia, C.; Li, F. Nickel-Catalyzed Alkynylation of a $\mathrm{C}\left(\mathrm{sp}^{2}\right)-\mathrm{H}$ Bond Directed by an 8-Aminoquinoline Moiety, J. Org. Chem. 2015, 80, 6213; (m) Landge, V. G.; Midya, S. P.; Rana, J.; Shinde, D. R.; Balaraman, E. Expedient CobaltCatalyzed C-H Alkynylation of (Enantiopure) Benzylamines, Org. Lett. 2016, 18, 5252; (n) Landge, V. G.; Shewale, C. H.; Jaiswal, G.; Sahoo, M. K.; Midya, S. P.; Balaraman, E. Nickel-catalyzed direct alkynylation of $\mathrm{C}\left(\mathrm{sp}^{2}\right)-\mathrm{H}$ bonds of amides: an "inverse Sonogashira strategy" to ortho-alkynylbenzoic acids, Catal. Synth. Techn. 2016 6, 1946; (o) Ruan, Z.; Lackner, S.; Ackermann, L. Nickel-Catalyzed $\mathrm{C}-\mathrm{H}$ Alkynylation of Anilines: Expedient Access to Functionalized Indoles and Purine Nucleobases, ACS Catal. 2016, 6, 4690; (p) Ye, X.; Xu, C.; Wojtas, L.; Akhmedov, N. G.; Chen, H.; Shi, X. Silver-Free Palladium-Catalyzed $\mathrm{sp}^{3}$ and $\mathrm{sp}^{2} \mathrm{C}-\mathrm{H}$ Alkynylation Promoted by a 1,2,3-Triazole Amine Directing Group, Org. Lett. 2016, 18, 2970; (q) Chen, C.; Liu, P.; Tang, J.; Deng, G.; Zeng, X. Iridium-Catalyzed, Weakly Coordination-Assisted Ortho-Alkynylation of (Hetero)aromatic Carboxylic Acids without Cyclization, Org. Lett. 2017, 19, 2474; (r) Mei, R.; Zhang, S.-K.; Ackermann, L. Ruthenium(II)-Catalyzed C-H Alkynylation of Weakly Coordinating Benzoic Acids, Org. Lett. 2017, 19, 3171; (s) Tan, E.; Konovalov, A. I.; Fernández, G. A.; Dorel, R.; Echavarren, A. M. RutheniumCatalyzed Peri- and Ortho-Alkynylation with Bromoalkynes via Insertion and Elimination, Org. Lett. 2017, 19, 5561; (t) Usui, K.; Haines, B. E.; Musaev, D. G.; Sarpong, R. Understanding Regiodivergence in a $\mathrm{Pd}(\mathrm{II})$-Mediated Site-Selective $\mathrm{C}-\mathrm{H}$ Alkynylation, ACS Catal. 2018, 8, 4516; (u) Wang, T.; Wang, Y.-N.; Wang, R.; Wang, X.-S. Rhodium(III)-Catalyzed C-H Alkynylation of N-Methylsulfoximines, Chem. Asian J. 2018, 13, 2449; (v) Zheng, Y.; Song, W. Pd-Catalyzed Site-Selective $\mathrm{C}\left(\mathrm{sp}^{2}\right)-\mathrm{H}$ Olefination and Alkynylation of Phenylalanine Residues in Peptides, Org. Lett. 2019, $21,3257$.

(9) This directed approach has been modified by Yu et al. to reach the meta position of aniline-derivatives, albeit still requiring the introduction of a specialized directing group : Wang, P.; Li, G.-C.; Jain, P.; Farmer, M. E.; He, J.; Shen, P.-X.; Yu, J.-Q. LigandPromoted meta-C-H Amination and Alkynylation, J. Am. Chem. Soc. 2016, 138, 14092.

(10) (a) Tse, M. K.; Cho, J.-Y.; Smith, M. R. Regioselective Aromatic Borylation in an Inert Solvent, Org. Lett. 2001, 3, 2831; (b) Cho, J.-Y.; Tse, M. K.; Holmes, D.; Maleczka, R. E.; Smith, M. R. Remarkably Selective Iridium Catalysts for the Elaboration of Aromatic C-H Bonds, Science 2002, 295, 305; (c) Chotana, G. A.; Rak, M. A.; Smith, M. R. Sterically Directed Functionalization of Aromatic $\mathrm{C}-\mathrm{H}$ Bonds: Selective Borylation Ortho to Cyano Groups in Arenes and Heterocycles, J. Am. Chem. Soc. 2005, 127, 10539.

(11) (a) Ishiyama, T.; Takagi, J.; Hartwig, J.; Miyaura, N. A Stoichiometric Aromatic C-H Borylation Catalyzed by Iridium(I)/2,2'-
Bipyridine Complexes at Room Temperature, Angew. Chem. Int. Ed. 2002, 41, 3056; (b) Ishiyama, T.; Nobuta, Y.; Hartwig, J. F.; Miyaura, $\mathrm{N}$. Room temperature borylation of arenes and heteroarenes using stoichiometric amounts of pinacolborane catalyzed by iridium complexes in an inert solvent, Chem. Commun. 2003, 2924.

(12) (a) Cheng, C.; Hartwig, J. F. Rhodium-Catalyzed Intermolecular $\mathrm{C}-\mathrm{H}$ Silylation of Arenes with High Steric Regiocontrol, Science 2014, 343, 853; (b) Cheng, C.; Hartwig, J. F. Iridium-Catalyzed Silylation of Aryl C-H Bonds, J. Am. Chem. Soc. 2015, 137, 592; (c) Lee, K.-s.; Katsoulis, D.; Choi, J. Intermolecular $\mathrm{C}-\mathrm{H}$ Silylation of Arenes and Heteroarenes with $\mathrm{HSiEt}_{3}$ under Operationally Diverse Conditions: Neat/Stoichiometric and Acceptor/Acceptorless, ACS Catal. 2016, 6, 1493; (d) Karmel, C.; Chen, Z.; Hartwig, J. F. Iridium-Catalyzed Silylation of C-H Bonds in Unactivated Arenes: A Sterically Encumbered Phenanthroline Ligand Accelerates Catalysis, J. Am. Chem. Soc. 2019.

(13) (a) Kuhl, N.; Hopkinson, M. N.; Wencel-Delord, J.; Glorius, F. Beyond Directing Groups: Transition-Metal-Catalyzed C-H Activation of Simple Arenes, Angew. Chem. Int. Ed. 2012, 51, 10236; (b) Hartwig, J. F.; Larsen, M. A. Undirected, Homogeneous C-H Bond Functionalization: Challenges and Opportunities, ACS Cent. Sci. 2016, 2, 281; (c) Wedi, P.; van Gemmeren, M. Arene-Limited Nondirected C-H Activation of Arenes, Angew. Chem. Int. Ed. 2018, 57,13016

(14) (a) Naksomboon, K.; Valderas, C.; Gómez-Martínez, M.; Álvarez-Casao, Y.; Fernández-lbáñez, M. Á. S,O-Ligand-Promoted Palladium-Catalyzed $\mathrm{C}-\mathrm{H}$ Functionalization Reactions of Nondirected Arenes, ACS Catal. 2017, 7, 6342; (b) Wang, P.; Verma, P.; Xia, G.; Shi, J.; Qiao, J. X.; Tao, S.; Cheng, P. T. W.; Poss, M. A.; Farmer, M. E.; Yeung, K.-S.; Yu, J.-Q. Ligandaccelerated non-directed $\mathrm{C}-\mathrm{H}$ functionalization of arenes, Nature 2017, 551, 489; (c) Chen, H.; Wedi, P.; Meyer, T.; Tavakoli, G.; van Gemmeren, M. Dual Ligand-Enabled Nondirected $\mathrm{C}-\mathrm{H}$ Olefination of Arenes, Angew. Chem. Int. Ed. 2018, 57, 2497; (d) Chen, H.; Mondal, A.; Wedi, P.; van Gemmeren, M. Dual Ligand-Enabled Nondirected C-H Cyanation of Arenes, ACS Catal. 2019, 9, 1979; (e) Chen, X.-Y.; Wu, Y.; Zhou, J.; Wang, P.; Yu, J.-Q. Synthesis of $\beta$-Arylethenesulfonyl Fluoride via Pd-Catalyzed Nondirected $\mathrm{C}-\mathrm{H}$ Alkenylation, Org. Lett. 2019; (f) Liu, L.; Yeung, K.-S.; Yu, J.-Q. Ligand-Accelerated Non-Directed C-H Cyanation of Arenes, Chem. Eur. J. 2019, 25, 2199; (g) Naksomboon, K.; Poater, J.; Bickelhaupt, F. M.; Fernández-lbáñez, M. Á. para-Selective C-H Olefination of Aniline Derivatives via $\mathrm{Pd} / \mathrm{S}$, O-Ligand Catalysis, J. Am. Chem. Soc. 2019; (h) Zhao, D.; Xu, P.; Ritter, T. Palladium-Catalyzed Late-Stage Direct Arene Cyanation, Chem 2019, 5, 97.

(15) Ghiringhelli, F.; Nattmann, L.; Bognar, S.; van Gemmeren, M. The Direct Conversion of a-Hydroxyketones to Alkynes, J. Org. Chem. 2019, 84, 983

(16) (a) Damle, S. V.; Seomoon, D.; Lee, P. H. PalladiumCatalyzed Homocoupling Reaction of 1-lodoalkynes: A Simple and Efficient Synthesis of Symmetrical 1,3-Diynes, J. Org. Chem. 2003, 68, 7085; (b) Chen, Z.; Jiang, H.; Wang, A.; Yang, S. TransitionMetal-Free Homocoupling of 1-Haloalkynes: A Facile Synthesis of Symmetrical 1,3-Diynes, J. Org. Chem. 2010, 75, 6700; (c) Nicolai, S.; Waser, J. Pd(0)-Catalyzed Oxy- and Aminoalkynylation of Olefins for the Synthesis of Tetrahydrofurans and Pyrrolidines, Org. Lett. 2011, 13, 6324; (d) Sindhu, K. S.; Thankachan, A. P.; Sajitha, P. S.; Anilkumar, G. Recent developments and applications of the CadiotChodkiewicz reaction, Org. Biomol. Chem. 2015, 13, 6891.

(17) (a) Guan, M.; Chen, C.; Zhang, J.; Zeng, R.; Zhao, Y. Palladium-catalyzed oxalyl amide assisted direct ortho-alkynylation of arylalkylamine derivatives at $\delta$ and $\varepsilon$ positions, Chem. Commun. 2015, 51, 12103; (b) Zhou, J.; Shi, J.; Qi, Z.; Li, X.; Xu, H. E.; Yi, W. Mild and Efficient $\operatorname{Ir}(\mathrm{III})$-Catalyzed Direct $\mathrm{C}-\mathrm{H}$ Alkynylation of $\mathrm{N}$ Phenoxyacetamides with Terminal Alkyne, ACS Catal. 2015, 5, 6999; (c) Tang, G.-D.; Pan, C.-L.; Xie, F. Ir(III)-catalyzed C-H alkynylation of arenes under chelation assistance, Org. Biomol. Chem. 2016, 14, 2898; (d) Hu, S.; Lu, L.; Zhu, T.; Wu, Q.; Chen, Y.; $\mathrm{Li}$, J. J.; Zhao, J. Rh(III)-Catalyzed ortho-C-H alkynylation of $\mathrm{N}$ phenoxyacetamides with hypervalent iodine-alkyne reagents at room temperature, Org. Biomol. Chem. 2018, 16, 43. 